Resenha de artigo

Article view

\title{
Atividade física e estados afetivos positivos em estudantes universitários durante a pandemia de CoViD-19: resenha apresentando o artigo de Maher et al.
}

\section{Physical Activity and Positive Affect in College Students during the CoViD-19 Pandemic: An Article View Presenting the Article by Maher et al.}

\section{Corpo Editorial REF/JPE}

Recebido em: 29 de dezembro de 2020. Aceito em: 30 de dezembro de 2020.

Publicado online em: 30 de dezembro de 2020.

DOI: $10.37310 /$ ref.v89i3.2712

\section{Resumo}

Introdução: Como parte da Edição Especial de 2020 I, a Revista de Educação Física / Journal of Physical Education (REF/JPE) está trazendo aspectos científicos da prática de atividade física relacionados à pandemia de CoViD-19.

Objetivo: 0 objetivo do presente trabalho foi apresentar e indicar a leitura do estudo de Maher et al. sobre a associação de atividade física com estados afetivos positivos em alunos universitários aos leitores da REF/JPE.

Conclusão: Os resultados mostraram que a prática de atividade física estava significativamente associada a estados afetivos positivos, ainda que em presença de eventos de vida estressantes. Recomenda-se a leitura desse relevante trabalho.

Palavras-chave: exercício físico, pandemia, estados afetivos, psicologia do esporte

\section{Abstract}

Introduction: As part of the Special Edition 2020 I, the Revista de Educação Física / Journal of Physical Education (REF / JPE)

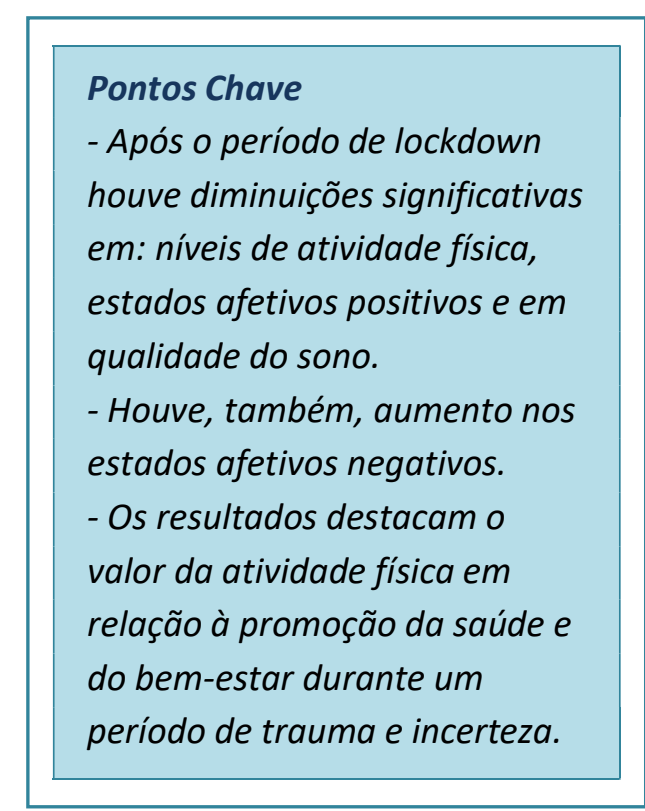
brings scientific aspects of the practice of physical activity related to the CoViD-19 pandemic.

Objective: The objective of this was to present and indicate the reading of the study by Maher et al. on the association of physical activity with positive affect in university students to REF / JPE readers.

Conclusion: The results showed that the practice of physical activity was significantly associated with positive affective states even in the presence of negative life events. Reading of this relevant work is recommended.

Keywords: physical exercise, pandemic, affective states, sport psychology.

\footnotetext{
$\S$ Autor correspondente: Corpo Editorial REF/JPE e e-mail: revistaef.ccfex@gmail.com Afiliações: ${ }^{1}$ centro de Capacitação Física do Exército (CCFEx), Rio de Janeiro - RJ, Brasil.
} 


\section{Atividade física e estados afetivos positivos em estudantes universitários durante a pandemia de CoViD-19: resenha apresentando o artigo de Maher et al.}

\section{Introdução}

O início do ano de 2020 foi marcado pela ocorrência de uma pandemia de uma nova doença: a SARS-CoV2 (Severe Acute Respiratory Syndrome: síndrome respiratória aguda severa, causada por um novo coronavírus, o CoV2). A doença foi assim denominada porque, em 2002, o mundo já havia conhecido a pandemia causada por um coronavírus a SARS-CoV, que teve origem em Guandong, na China(1). Em dezembro de 2019, desta vez na província de Wuhan (China), registrou-se o primeiro caso de infecção pelo Cov2(2). O vírus também causa SARS, porém, apresenta diversas outras características distintas, em comparação com o vírus anterior(3). Assim, a nova doença ficou conhecida como CoViD-19 (Corona Virus Disease from 2019).

Como parte da Edição Especial de 2020 parte I, a Revista de Educação Física / Journal of Physical Education (REF/JPE) está trazendo aspectos científicos da prática de atividade física relacionada à pandemia.

O objetivo do presente trabalho foi apresentar e indicar a leitura do estudo de Maher et al.(4) aos leitores da REF/JPE.

\section{Desenvolvimento}

$\mathrm{O}$ artigo intitulado "Physical Activity is Positively Associated with College Students' Positive Affect Regardless of Stressful Life Events during the COVID-19 Pandemic" de Maher et al.(4) foi recentemente publicado (17 de outubro de 2020) em um periódico internacional. $\mathrm{O}$ objetivo do estudo foi determinar o efeito antes e durante o período de permanência em casa (lockdown) do CoViD-19 sobre os níveis de atividade física e associações com estados afetivos, em estudantes universitários.

O estudo foi do tipo observacional, longitudinal, conduzido em uma universidade da Carolina do Norte, Estados Unidos da América $(\mathrm{n}=107)$, em amostragem por

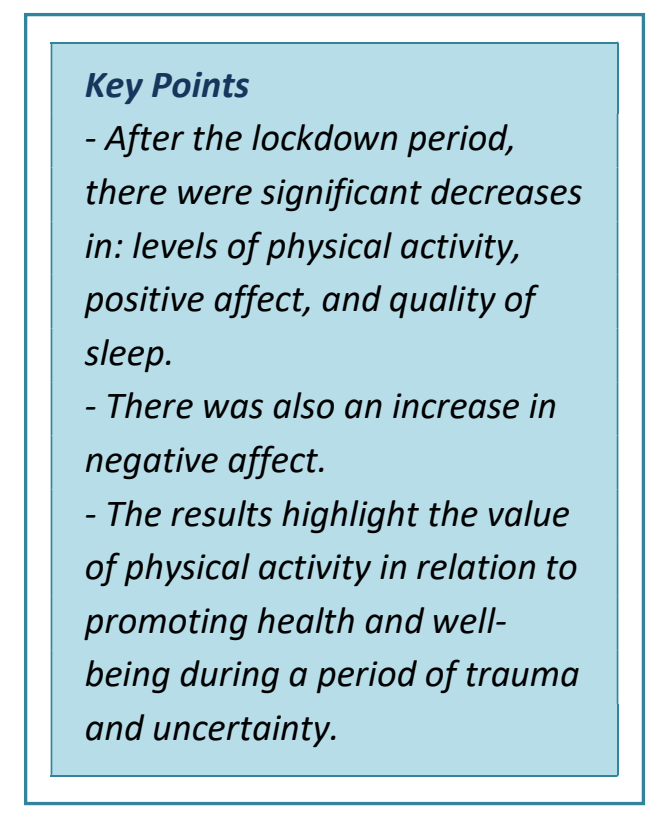

conveniência. A pesquisa foi do tipo levantamento online, por meio de questionário.

Os autores, à exceção das características demográficas, utilizaram escalas validadas para avaliar todas as variáveis do estudo (estados afetivos positivos e negativos, qualidade do sono, segurança alimentar e eventos de vida estressantes). A avaliação de nível de atividade física utilizou o Questionário Internacional de Atividade Física (International Physical Activity Questionnaire - Short Form), o IPAQ-SF(5).

A coleta de dados foi realizada em dois momentos: entre janeiro e março de 2020: T1; e entre abril e maio de 2020: T2

Os principais achados foram que, após o período de lockdown examinado, determinado em função da COViD-19, houve diminuições significativas em níveis de atividade física, estados afetivos positivos e em qualidade do sono. Além disso, houve aumento nos estados afetivos negativos.

Os resultados foram discutidos e os autores concluíram que os achados apontam para o valor da atividade física em relação à promoção da saúde e do bem-estar durante um período de trauma e incerteza. Além disso, sugerem que pesquisas adicionais sejam conduzidas em outras populações de adultos. A 
Figura 1 apresenta a página de face do $\operatorname{artigo(4).~}$

\section{Conclusão}

$\mathrm{O}$ estudo de Maher et al.(4) mostrou que a prática de atividade física associa-se a estados afetivos positivos mesmo em presença de eventos de vida estressantes. A amostra foi composta de alunos universitários de tamanho amostral de 107 participantes. Apesar de se tratar de uma população bastante restrita, os resultados do estudo, corroboram o amplo corpo de evidências científicas no sentido de que a prática de atividade física favorece a saúde mental e o bem-estar(6-8). Assim, é importante que a ciência oriente as ações em saúde considerando o enfoque de incentivar as mais distintas populações a buscarem estar fisicamente ativas.

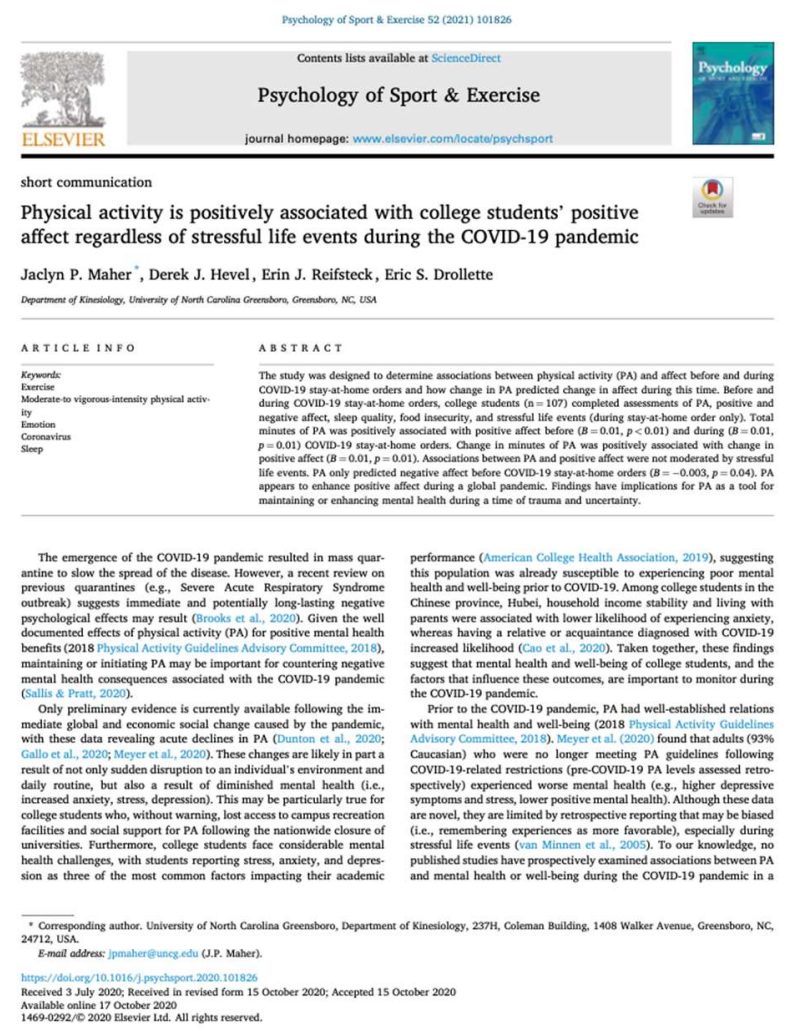

Figura 1 - Maher et al.(4). disponível em: doi:10.3390/ijerph17217964

\section{Declaração de conflito de interesses}

Não há nenhum conflito de interesses no presente estudo.

\section{Declaração de financiamento}

Estudo conduzido sem financiamento.

\section{Referências}

1. Stadler K, Masignani V, Eickmann M, Becker S, Abrignani S, Klenk H-D, et al. SARS--beginning to understand a new virus. Nature Reviews. Microbiology. [Online] 2003;1(3): 209-218. Available from: doi:10.1038/nrmicro775

2. Huang C, Wang Y, Li X, Ren L, Zhao J, $\mathrm{Hu} \mathrm{Y}$, et al. Clinical features of patients infected with 2019 novel coronavirus in Wuhan, China. Lancet (London, England). [Online] 2020;395(10223): 497-506. Available from: doi:10.1016/S0140-6736(20)30183-5

3. Liu S-L, Saif L. Emerging Viruses without Borders: The Wuhan Coronavirus. Viruses. [Online] 2020;12(2). Available from: doi:10.3390/v12020130

4. Maher JP, Hevel DJ, Reifsteck EJ, Drollette ES. Physical activity is positively associated with college students' positive affect regardless of stressful life events during the COVID-19 pandemic. Psychology of Sport and Exercise. [Online] 2021;52: 101826. Available from: doi:10.1016/j.psychsport.2020.101826

5. Craig CL, Marshall AL, Sjöström $M$, Bauman AE, Booth ML, Ainsworth BE, et al. International Physical Activity Questionnaire: 12-Country Reliability and Validity. Medicine \& Science in Sports \& Exercise. [Online] 2003;35(8): 13811395. Available from: doi:10.1249/01.MSS.0000078924.61453. FB

6. Schuch FB, Vancampfort D, Rosenbaum S, Richards J, Ward PB, Veronese N, et al. Exercise for depression in older adults: a meta-analysis of randomized controlled trials adjusting for publication bias. Revista Brasileira De Psiquiatria (Sao Paulo, Brazil: 1999). [Online] 2016;38(3): 247-254. Available from: doi:10.1590/1516-4446-2016-1915

7. Burtscher J, Burtscher M, Millet GP. (Indoor) isolation, stress, and physical 
inactivity: Vicious circles accelerated by COVID-19? Scandinavian Journal of Medicine \& Science in Sports. [Online] 2020;30(8): 1544-1545. Available from: doi:10.1111/sms.13706

8. Hamer M, Stamatakis E, Steptoe A. Doseresponse relationship between physical activity and mental health: the Scottish Health Survey. British Journal of Sports Medicine. [Online] 2009;43(14): 11111114. Available from: doi:10.1136/bjsm.2008.046243 